\title{
Does mandatory reporting legislation increase contact with child protection? - a legal doctrinal review and an analytical examination
}

\author{
Lil Tonmyr ${ }^{1 *}$ (D, Ben Mathews ${ }^{2}$, Margot E. Shields ${ }^{1}$, Wendy E. Hovdestad ${ }^{1}$ and Tracie O. Afifi ${ }^{3}$
}

\begin{abstract}
Background: Within Canadian provinces over the past half-century, legislation has been enacted to increase child protection organization (CPO) involvement in situations of child maltreatment (CM). This study had two objectives: 1) to document enactment dates of legislation for mandatory reporting of $\mathrm{CM} ; 2$ ) to examine reported $\mathrm{CPO}$ involvement among people reporting a CM history in relation to the timing of these legislative changes.

Methods: The history of mandatory reporting of CM was compiled using secondary sources and doctrinal legal review of provincial legislation. The 2012 Canadian Community Health Survey - Mental Health (CCHS-MH) with $n=18,561$ was analyzed using birth cohorts to assess associations between the timing of legislation enactment and contact with CPO.

Results: All Canadian provinces currently have mandatory reporting of physical and sexual abuse; 8 out of 10 provinces have mandatory reporting for children's exposure to intimate partner violence. Increases in reporting CM to CPOs paralleled these laws' enactment, particularly for severe and frequent CM.

Conclusions: These findings show that mandatory reporting laws increase reporting contact with CPO, particularly for severe and frequent CM. Whether they have had the intended effect of improving children's lives remains an important, unanswered question.
\end{abstract}

Keywords: Child maltreatment, Exposure to intimate partner violence, Sexual abuse, Physical abuse, Mandatory reporting, Child welfare, Doctrinal legal review

\section{Background}

In Canada today, child maltreatment (CM) occurs in every stratum of society. The negative impacts pose serious immediate and long-term risks to the health and development of its victims [1]. CM impedes healthy development and negatively impacts mental and physical health [1]. It also increases the likelihood of unhealthy behaviors, such as smoking and substance use [2-4]. CM and associated problems are threats to public health.

$\mathrm{CM}$ is by no means a rare occurrence. Results from the Canadian Community Health Survey-Mental Health Survey (CCHS-MH) conducted in 2012 indicate that at

\footnotetext{
* Correspondence: Lil.Tonmyr@canada.ca

${ }^{1}$ Public Health Agency of Canada, 785 Carling Ave, AL 6807B, Ottawa, ON

K1A OK9, Canada

Full list of author information is available at the end of the article
}

least $32 \%$ of the adult Canadian population experienced one or more types of childhood maltreatment [5]. Childhood physical abuse (CPA) was the most common form of $\mathrm{CM}-$ reported by $26 \%$ of CCHS-MH respondents, followed by sexual abuse (CSA), reported by $10 \%$, and exposure to intimate partner violence (CEIPV), by $8 \%$ [5]. Neglect and emotional maltreatment were not captured in the 2012 CCHS-MH.

Within a few decades of Canada's confederation, child protection organizations (CPOs) were introduced. The inception and development of CPOs occurred at different times across the provinces. The first general frameworks for child welfare were established in 1893 in Ontario, in 1902 in Manitoba, and 1906 in Nova Scotia [6]. While the initial focus was primarily on preventing neglected children from having to subsist in the streets, 
advances in the 1960s and 1970s broadened systemic welfare strategies [7]. One such development was the implementation of laws requiring reporting of $\mathrm{CM}$, similar to those introduced in the 1960s in the United States. These laws were enacted in the provinces at different times and varied in content [7]. Mandatory legislation has been successfully implemented as a public health strategy in other domains such as the requirement for immunizations for children attending school [8].

Despite mandatory reporting legislation, evidence suggests that only a small share of CM is brought to the attention of CPOs. Based on a study of the population aged 15 years or older conducted in the province of Ontario in 1990/1991 [9], reports of contact with a CPO were $5.1 \%$ among those with a history of CPA, and $8.7 \%$ among those with a history of CSA. A similar study using data collected in the 10 Canadian provinces from the 2012 CCHS-MH [10] indicated that the likelihood of $\mathrm{CPO}$ contact was slightly higher, $8.0 \%$ among those with a history of CPA, $10.4 \%$ among those with a history of CSA and 16.6\% among those with a history of CEIPV (CEIPV was not captured in the earlier study conducted in Ontario). Among those with a history of all three types of CM (CPA, CSA and CEIPV), contact was reported by $24.5 \%$.

Although little is known about the effectiveness of $\mathrm{CPO}$ interventions in deterring $\mathrm{CM}$, and improving health and social outcomes [1], it is important to understand how legislative changes may influence reporting practices. The objectives of this study are: 1) to examine the history of legislative changes and the key elements of $\mathrm{CM}$ mandatory reporting laws in Canada; and 2) to examine the likelihood of reporting contact with a CPO among people reporting a history of $\mathrm{CM}$ in relation to the date of enactment of mandatory reporting legislation. The higher reporting rates observed in the study based on the 2012 CCHS-MH [10] compared with the earlier Ontario study from 1990 [9] suggests that the likelihood of CM being reported to CPOs has increased over time. To explore this hypothesis, we examine reporting rates by age cohorts among CCHS-MH respondents.

\section{Methods}

\section{Doctrinal legal review}

Doctrinal legal research can involve a literature review but also requires a trained expert in legal doctrine to read and analyse the primary sources of law [11]. Our analysis of the law was necessarily focused on legislation as a primary source, since child protection is regulated by legislation rather than case law. Any judicial decisions about the legislation would have added little useful information. An initial scan of the legislative history and framework in each province was undertaken by identifying secondary source coverage of child protection legislation in legal and social science databases [7, 12-14]. Then, the actual legislation for each province was reviewed, using electronic legislation databases and orthodox legal analysis using principles of statutory interpretation. Because electronic databases do not contain records of legislation from the 1960s, a hand search was carried out in August 2016 in a specialized law library for hard copies of legislation for each province. This strategy enabled identification of the relevant legislation.

Analysis of multiple provisions in each piece of legislation then enabled identification of the mandatory reporting duty and its wording and scope, the definition of key concepts such as "abuse", "neglect" and "child in need of protection," and the commencement date of the legislation. That is, multiple relevant parts of each statute were analyzed to identify the discrete provisions in each that detail the reporting duty, and associated provisions which define relevant terms which further establish and elucidate the nature and scope of the duty. In a number of cases, it was not possible to definitively identify subsequent amending legislation and its precise commencement date, although this generally applied to jurisdictions with small populations (i.e., Newfoundland and Labrador, Prince Edward Island). Where this occurred, triangulation of the analysis with conclusions drawn from secondary sources was used to confirm the interpretation.

It is noteworthy that legal provisions are often ambiguous, and while reporting laws were generally unequivocal, questions arose for some jurisdictions about whether the reporting duty applied to CSA. In such instances, conventional technical principles of statutory interpretation were applied to draw conclusions, based on the legislation's text, context, and purpose. ${ }^{1}$

\section{CCHS data set and analysis \\ CCHS data}

The 2012 CCHS-MH [15] was used to address the question of whether the enactment of laws requiring mandatory reporting of $\mathrm{CM}$ was associated with changes in the likelihood of CPO involvement in cases of CM. The CCHS-MH was developed by Statistics Canada in collaboration with Health Canada, the Public Health Agency of Canada, provincial health ministries, an expert advisory group, and academic experts.

The target population for the 2012 CCHS-MH comprised household residents aged 15 or older living in the 10 Canadian provinces. Excluded from the survey's coverage were persons living on reserves and other Aboriginal settlements, full-time members of the Canadian Forces and the institutionalized population. Due to the nature of the questions asked in the CCHS-MH, proxy responses were not permitted making it necessary to exclude the institutionalized population. There are complexities regarding obtaining permission to conduct in-person interviews on military 
sites and reserves and therefore people living in these jurisdictions were excluded. Another reason to exclude the Canadian Forces is that they have a distinct health system and a separate health survey. Altogether, these exclusions represent about $3 \%$ of the target population. The response rate was $68.9 \%$, yielding a sample of 25,113 individuals aged 15 or older [15]. This analysis is based on the "share" file ( $n$ $=23,709 ; 94 \%$ ), a subset of the sample consisting of the records of respondents who agreed that their information could be shared with Statistics Canada's partners. The majority of interviews $(87 \%)$ were conducted in person using computer assisted interviewing.

Inclusion and exclusion criteria The questions on CM were asked of respondents aged 18 or older $(n=22,486)$. Immigrants to Canada were excluded from the analysis (since it was not determined if CM occurred before or after immigration to Canada), reducing the sample size for this study to 18,561 . Non-response to the individual questions on $\mathrm{CM}$ ranged from 0.9 to $1.2 \%$; non-response to the item on contact with a CPO was $0.3 \%$.

Informed consent Respondents were informed about privacy, confidentiality and voluntary participation for the survey and provided informed consent prior to their participation [16].

\section{Measures}

CM variables The occurrence of CPA, CSA and CEIPV was assessed by asking respondents about specific experiences ("things that may have happened to you before you were 16 in your school, in your neighbourhood, or in your family") (Fig. 1). The source of the items for CPA and CEIPV is the Childhood Experiences of Violence Questionnaire (CEVQ) [17]. The CSA items are very similar to those used in the 2009 General Social Survey [18]. For each type of abuse, binary variables (yes/no) were created following CEVQ guidelines [17]. Contact with a child protection organization (CPO) was determined with the question, "Before age 16, did you ever see or talk to anyone from a child protection organization about difficulties at home?"

Socio-demographic variables The socio-demographic characteristics used as controls in logistic regression models included, sex, respondent's highest level of education (less than secondary graduation, secondary graduation, some postsecondary, postsecondary graduation), household income (quintiles based on household income adjusted by Statistics Canada's low income cutoffs (LICO) specific to the number of individuals in the household, the size of the community, and the survey year), ethnicity (White, non-White) and province of residence at the time of the survey.

\section{Analysis}

Among individuals reporting CM, cross-tabulations were used to examine associations between year of birth and reporting contact with a CPO. Cohorts based on year of birth were established to examine any difference in the percentage of people reporting contact with a $\mathrm{CPO}$ before and after 1965-the year mandatory reporting was first implemented in Canada (in the province of Ontario). The following detailed birth cohorts were defined by year of birth:

- 1939 or earlier (age > = 26 years in 1965)

- 1940-1949 (age 16-25 years in 1965)

- 1950-1957 (age 8-15 years in 1965)

- 1958-1965 (age 0-7 years in 1965)

- 1966-1974 (born 1-9 years after 1965 legislation)

- 1975-1984 (born 10-19 years after 1965 legislation)

- 1985-1994 (born 20-29 years after 1965 legislation)

In people reporting any type of $\mathrm{CM}$ within each of these detailed birth cohorts, the percentage reporting contact with a CPO was estimated. We also examined percentages reporting $\mathrm{CPO}$ contact for specific types of $\mathrm{CM}$ but sample sizes were too small and therefore, to enlarge the cell sizes and thereby increase the stability of $\mathrm{CM}$-specific estimates, the birth cohorts were more broadly defined. These analyses focused on CPO contact rates among respondents born after 1965 (when mandatory reporting was introduced in Canada), but before or during the year mandatory reporting was implemented in the respondent's province of residence at the time of the survey. The broad birth cohorts derived for estimates pertaining to specific types of $\mathrm{CM}$ were:

- born before or during 1965

- born after 1965, but before or during the year mandatory reporting was implemented in current province of residence

- born after the year mandatory reporting was implemented in current province of residence.

For this broader categorization, cross-tabulations and logistic regression (controlling for selected socio-demographic characteristics) were used to examine associations between year of birth and contact with a CPO among people reporting specific types of $\mathrm{CM}$, as well as frequency and severity of CM.

Analyses were conducted using SAS Enterprise Guide 5.1. All estimates were based on weighted data. Weights were created at Statistics Canada so that the data would be representative of the Canadian population living in the ten provinces in 2012 and were adjusted to compensate for non-response. Variance estimates and 95\% confidence intervals (CIs) were calculated using the bootstrap technique 


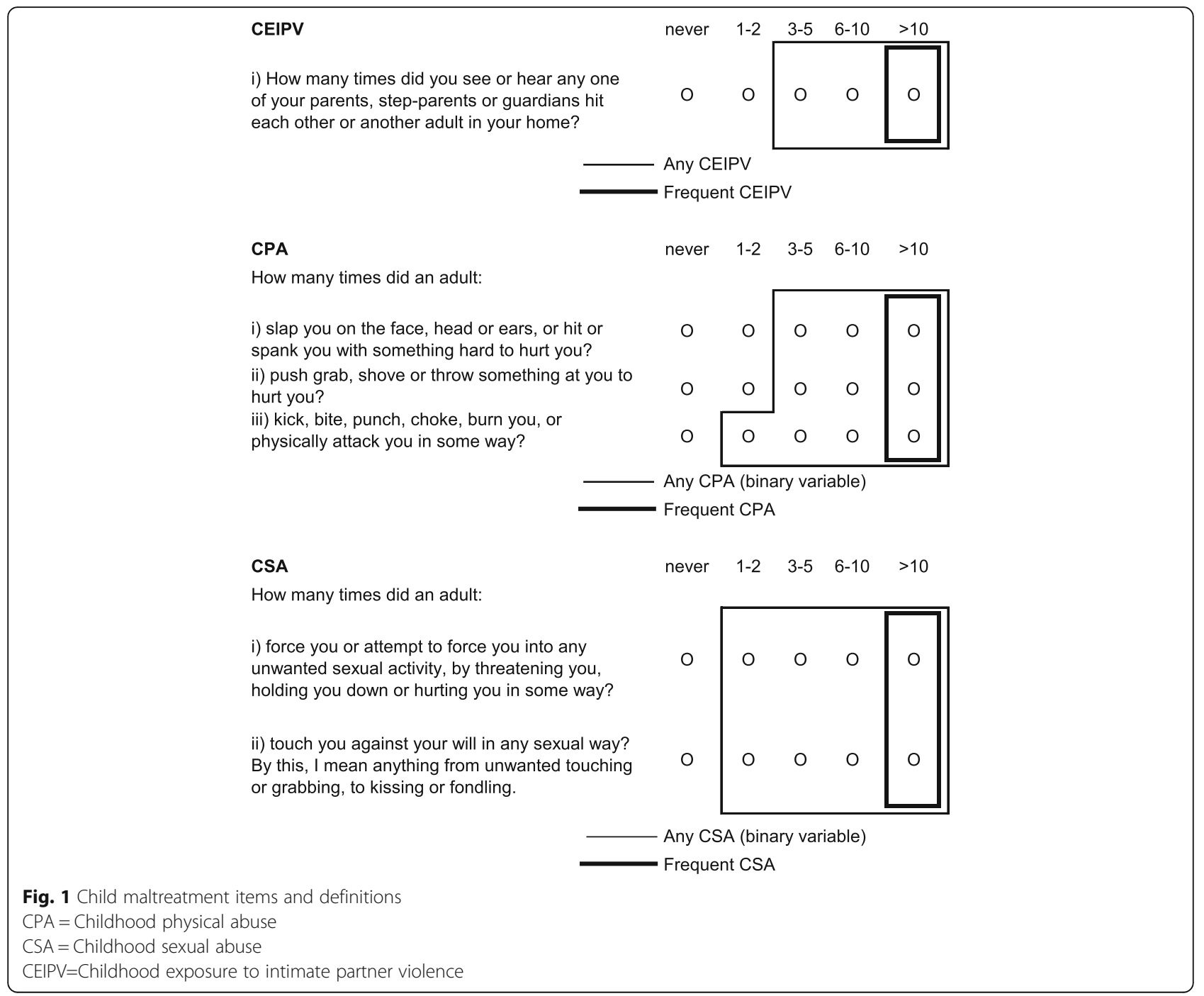

(with the SAS "proc survey" procedures) to account for the complex survey design of the CCHS-MH [15].

\section{Results}

\section{Doctrinal legal review}

Doctrinal and historical analysis of provincial legislation indicated that duties to report CPA and CSA of children have been enacted in each province, but at different times. The first mandatory reporting laws appeared in Ontario in 1965, followed by Alberta in 1966, and other jurisdictions soon thereafter. The initial laws focused predominantly on child neglect, CPA or ill-treatment, and other indications of being "in need of protection," which itself was variously defined. Duties to report CSA have also been enacted, sometimes explicitly, or else by implication. At this early stage, no jurisdiction expressly acknowledged CEIPV, nor would it have been incorporated by implication.

The area of greatest variation pertained to the duty to report CEIPV. At the time of writing, eight of the ten provinces expressly required reports of exposure of a child to domestic violence or intimate partner violence. The timing of the introduction of this duty varied substantially, from 1973 in Saskatchewan until most recently in June 2014. Three jurisdictions (i.e., New Brunswick and Ontario) still do not explicitly require reports of CEIPV.

The four most populous Canadian jurisdictions, Alberta, British Columbia, Ontario, and Quebec, account for over $85 \%$ of the national population [19]. Three of these jurisdictions - Alberta, British Columbia, and Ontario - enacted mandatory reporting duties at around the same time in 1965 to 1967, with Quebec following almost a decade later. In these jurisdictions, the legislation pertaining to CPA and CSA is similar, although not for CEIPV. The scope of the legislation and commencement dates of the mandatory reporting duties for each type of maltreatment in the ten provinces is summarized in Table 1, below. 
Table 1 Scope and commencement dates of legislative mandatory reporting duties for physical abuse, sexual abuse, and exposure to intimate partner violence: Canadian provinces

\begin{tabular}{|c|c|c|c|}
\hline Jurisdiction & Physical abuse & Sexual abuse & $\begin{array}{l}\text { Exposure to domestic violence (or family } \\
\text { violence, or intimate partner violence) }\end{array}$ \\
\hline Alberta & 7 April 1966 & 7 April 1966 & 31 May 1984 \\
\hline British Columbia & 23 March 1967 & 23 March 1967 & 1 June 2014 \\
\hline Manitoba & 10 June 1974 & 10 June 1974 & At latest by 1 January $2003^{a, b}$ \\
\hline New Brunswick & 16 July 1980 & 16 July 1980 & Not mandated \\
\hline Newfoundland \& Labrador & 5 May 1972 & 5 May 1972 & $1981^{a}$ \\
\hline Nova Scotia & 20 May 1976 & 20 May 1976 & 19 June 1990 \\
\hline Ontario & 22 June 1965 & 22 June 1965 & Not mandated \\
\hline Prince Edward Island & 24 April 1981 & 24 April 1981 & At latest by 1 November $2003^{c}$ \\
\hline Quebec & 28 December 1974 & 28 December 1974 & 9 July 2007 \\
\hline Saskatchewan & 27 April 1973 & 27 April 1973 & 27 April 1973 \\
\hline
\end{tabular}

anable to pinpoint commencement date: year/time indicated is based on secondary sources [42] and analysis of available legislative materials

${ }^{b}$ While the statute did not expressly apply to exposure to domestic violence, its broad provisions read together produced a legitimate interpretation that the duty applied to this exposure, and that this accorded with the understanding of stakeholders

cs 3(f) of the definition of "child in need of protection" in the Child Protection Act version current to 1 November 2003, and s 22 mandatory reporting duty applying to a "child in need of protection" (electronic version of Act on CanLII current to this date). A search of PEI Hansard indicates no identifiable discussion of legislative developments prior to this date

\section{Statistical analysis of CCHS-MH data CPO contact by detailed birth cohorts}

Among non-immigrants who reported CM, 8.6\% reported having had contact with a CPO. In our analysis of detailed birth cohorts, percentages reporting contact with CPO (Fig. 2) were very low (<5\%) for cohorts born before/during 1965. For those born 1 to 9 years after the 1965 legislation, CPO contact increased sharply, with $12.6 \%$ reporting CPO involvement. Further increases were observed for younger cohorts, with $18.6 \%$ reporting $\mathrm{CPO}$ involvement among those born 20 or more years after the 1965 legislation.

\section{CPO contact by broad birth cohorts}

Table 2 presents the results when CPO involvement was examined using the more broadly defined cohorts in relation to age when mandatory reporting was first introduced in Canada as well as the respondent's current province of residence. Among people born before or in 1965 who reported a history of CM, only $4.1 \%$ reported CPO involvement. This percentage increased to $8.6 \%$ among those born after 1965, but before or during the year mandatory reporting was first introduced in the current providence of residence, and to $15.3 \%$ among those born after mandatory reporting was introduced in the current province of residence.

CPO contact by broad birth cohorts for specific types of CM A similar pattern emerged between birth year and CPO contact for the specific types of maltreatment. The sharpest increases in rates of CPO contact were observed in those reporting more than one type of $\mathrm{CM}$ and for more severe forms of CM. For example, among respondents who reported all three types of CM (CPA, CSA and CEIPV), $16.6 \%$ of those born before or during 1965 reported CPO involvement. Among those born after the year mandatory reporting legislation was introduced in their current province of residence, close to half (47.8\%) reported CPO involvement. Among respondents who reported being kicked, bitten, punched, choked, burned or attacked more than 10 times, CPO involvement rates increased from $11.6 \%$ for those who were born before or during 1965 to $43.9 \%$ for those born after the year mandatory reporting legislation was introduced in their current province of residence. Although sample counts were low for those reporting frequent abuse (as indicated by the wide confidence intervals), the sharp increases in rates observed for all CM types provides compelling evidence that the legislation had an impact.

\section{CPO contact by those reporting no CM}

As expected, reporting contact with a $\mathrm{CPO}$ was rare (1.9\%) among those with no history of the three measured types of CM. However, the rate was slightly higher (2.9\%) for those born after mandatory reporting was introduced in the current province of residence compared with those born before/during 1965 (1.1\%).

\section{Results of logistic regressions}

Among those reporting CM, associations between the broadly defined birth cohorts and reporting contact with a CPO were examined in logistic regression models. To examine the possible impact of socio-demographic factors on the magnitude of associations, unadjusted odds were calculated first, and then the control variables were included in the models. The odds of reporting CPO 


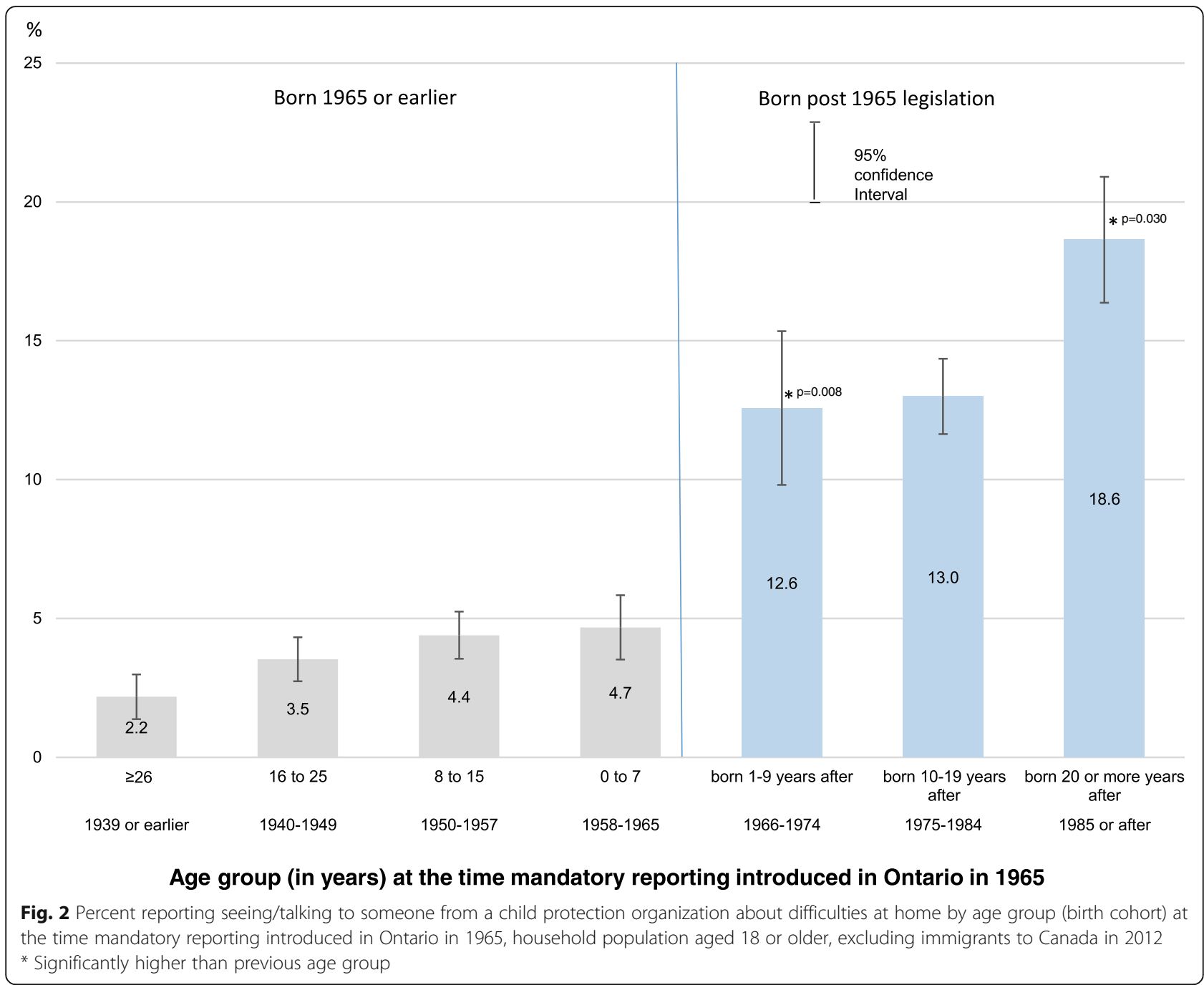

involvement were consistently higher among those born after the year mandatory reporting legislation was introduced in their current province of residence. For example, among respondents reporting any $\mathrm{CM}$, in the fully adjusted model, those who were born after the year mandatory reporting legislation was introduced in their current province of residence had 4.2 times the odds of reporting $\mathrm{CPO}$ involvement compared with those born before/during the year mandatory reporting was first introduced in Canada; among those reporting all three types of $\mathrm{CM}$ the corresponding odds were 5.4 times higher (Table 3).

\section{Discussion}

Ontario was the first province to introduce mandatory reporting legislation for CPA and CSA in 1965, quickly followed by Alberta and British Columbia. By 1981 all Canadian provinces had mandatory reporting for CPA and CSA. In 1973, Saskatchewan was the first province to mandate reporting of CEIPV. By 2014, all provinces except for Ontario and New Brunswick had enacted legislation requiring reporting of CEIPV.

Analysis of CCHS-MH retrospective data strongly suggests that the legal requirements to report suspected $\mathrm{CM}$ to child welfare services had an impact on CPO involvement. For those CCHS-MH respondents who had experienced $\mathrm{CM}$, more of those who were born after 1965 reported having had contact with CPO than those born before mandatory reporting legislation was introduced in 1965. The influence of the 1965 legislation appears to have spread well beyond the borders of Ontario-to jurisdictions that had not yet introduced mandatory reporting. The subsequent introduction of legislation in other provinces and expansion of the mandate to report suspected CM likely further encouraged $\mathrm{CPO}$ involvement. Furthermore, the seriousness and frequency of maltreatment was directly related to the likelihood of CPO contact.

The importance of mandatory legislation to increasing the reporting of $\mathrm{CM}$ and identification of cases has been 


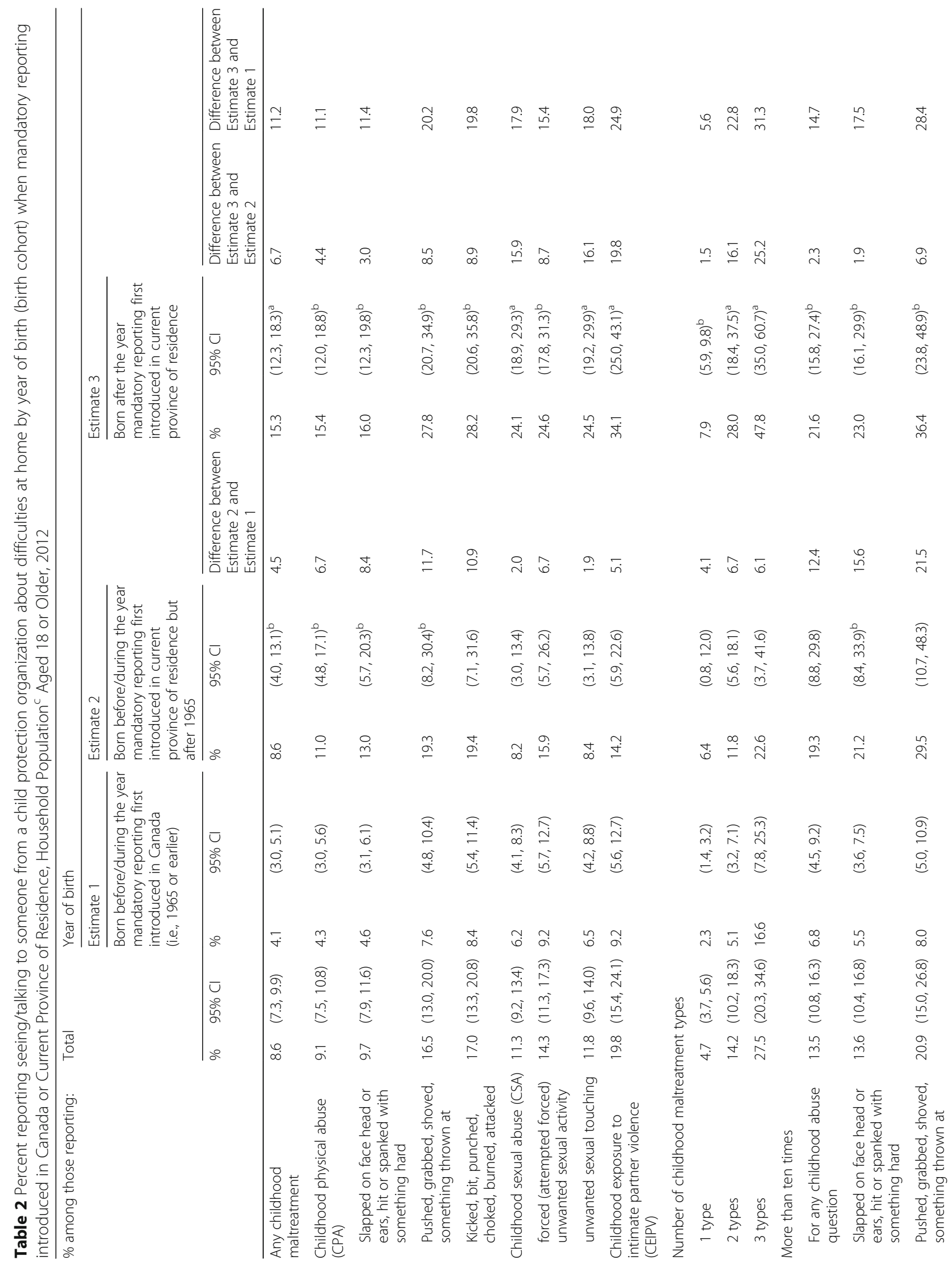




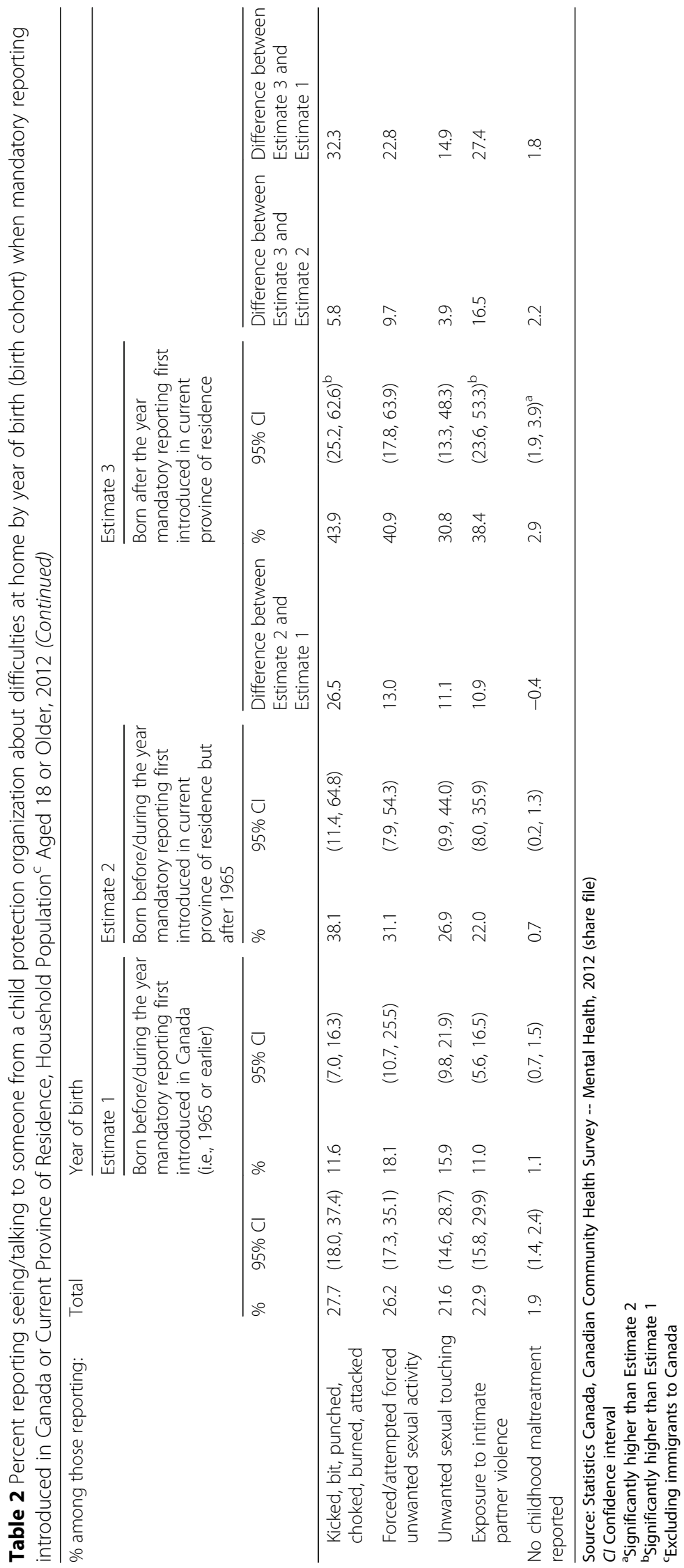


Table 3 Unadjusted and adjusted ${ }^{a}$ odds ratios for reporting seeing/talking to someone from a child protection organization about difficulties at home by age group at the time mandatory reporting introduced in Ontario in 1965/first introduced in current province of residence, household population ${ }^{\mathrm{b}}$ aged 18 or older, 2012

\begin{tabular}{|c|c|c|c|c|c|c|c|c|c|}
\hline \multirow[b]{4}{*}{ Odds among those reporting: } & \multicolumn{9}{|l|}{ Year of birth } \\
\hline & \multirow{3}{*}{$\begin{array}{l}\text { Born before/ during the year } \\
\text { mandatory reporting first } \\
\text { introduced in Canada } \\
\text { (i.e., } 1965 \text { or earlier) } \\
\text { (reference) }\end{array}$} & \multicolumn{4}{|c|}{$\begin{array}{l}\text { Born before/during the year } \\
\text { mandatory reporting first } \\
\text { introduced in current province } \\
\text { of residence but after } 1965\end{array}$} & \multicolumn{4}{|c|}{$\begin{array}{l}\text { Born after the year mandatory } \\
\text { reporting first introduced in } \\
\text { current province of residence }\end{array}$} \\
\hline & & \multicolumn{2}{|c|}{ Unadjusted Odds } & \multicolumn{2}{|c|}{ Adjusted Odds } & \multicolumn{2}{|c|}{ Unadjusted Odds } & \multicolumn{2}{|c|}{ Adjusted Odds } \\
\hline & & Odds & $95 \% \mathrm{Cl}$ & Odds & $95 \% \mathrm{Cl}$ & Odds & $95 \% \mathrm{Cl}$ & Odds & $95 \% \mathrm{Cl}$ \\
\hline Any childhood maltreatment & & $2.2^{*}$ & $(1.2,4.2)$ & $2.3^{*}$ & $(1.2,4.4)$ & $4.3^{* *}$ & $(3.0,6.1)$ & $4.2^{* *}$ & $(2.9,6.1)$ \\
\hline Childhood physical abuse (CPA) & & $2.7^{* *}$ & $(1.4,5.5)$ & $3.2^{* *}$ & $(1.5,6.7)$ & $4.0^{* *}$ & $(2.7,6.1)$ & $4.0^{* *}$ & $(2.6,6.2)$ \\
\hline $\begin{array}{l}\text { Slapped on face head or ears, hit or } \\
\text { spanked with something hard }\end{array}$ & & $3.1^{* *}$ & $(1.5,6.3)$ & $3.8^{* *}$ & $(1.8,8.2)$ & $3.9^{* *}$ & $(2.5,6.1)$ & $4.0^{* *}$ & $(2.5,6.3)$ \\
\hline $\begin{array}{l}\text { Pushed, grabbed, shoved, something } \\
\text { thrown at }\end{array}$ & & $2.9^{*}$ & $(1.3,6.6)$ & $3.7^{* *}$ & $(1.5,9.0)$ & $4.7^{* *}$ & $(2.8,7.8)$ & $4.2^{* *}$ & $(2.6,7.0)$ \\
\hline $\begin{array}{l}\text { Kicked, bit, punched, choked, burned, } \\
\text { attacked }\end{array}$ & & $2.6^{*}$ & $(1.0,6.5)$ & $3.4^{*}$ & $(1.3,9.2)$ & $4.3^{* *}$ & $(2.5,7.2)$ & $3.9^{* *}$ & $(2.4,6.4)$ \\
\hline Childhood sexual abuse (CSA) & & 1.3 & $(0.6,2.9)$ & 1.3 & $(0.6,2.8)$ & $4.8^{* *}$ & $(3.0,7.6)$ & $4.1^{* *}$ & $(2.5,6.7)$ \\
\hline $\begin{array}{l}\text { forced (attempted forced) unwanted } \\
\text { sexual activity }\end{array}$ & & 1.9 & $(0.8,4.5)$ & 1.7 & $(0.7,4.4)$ & $3.2^{* *}$ & $(1.8,5.7)$ & $2.6^{* *}$ & $(1.5,4.8)$ \\
\hline unwanted sexual touching & & 1.3 & $(0.6,2.9)$ & 1.3 & $(0.6,2.8)$ & $4.7^{* *}$ & $(2.9,7.5)$ & $4.0^{* *}$ & $(2.4,6.7)$ \\
\hline $\begin{array}{l}\text { Childhood exposure to intimate partner } \\
\text { violence (CEIPV) }\end{array}$ & & 1.6 & $(0.7,3.8)$ & 1.9 & $(0.7,4.9)$ & $5.1^{* *}$ & $(2.8,9.3)$ & $5.3^{* *}$ & $(3.0,9.5)$ \\
\hline \multicolumn{10}{|l|}{ Number of childhood maltreatment types } \\
\hline 1 type & & 2.9 & $(1.0,8.6)$ & 2.6 & $(0.9,7.9)$ & $3.6^{* *}$ & $(2.2,5.9)$ & $3.7^{* *}$ & $(2.2,6.2)$ \\
\hline 2 types & & $2.5^{*}$ & $(1.2,5.0)$ & $2.5^{*}$ & $(1.1,5.4)$ & $7.2^{* *}$ & $(3.9,13.3)$ & $6.4^{* *}$ & $(3.6,11.4)$ \\
\hline 3 types & & 1.5 & $(0.3,6.3)$ & 1.8 & $(0.4,7.3)$ & $4.6^{* *}$ & $(2.0,10.6)$ & $5.4^{* *}$ & $(2.1,13.6)$ \\
\hline \multicolumn{10}{|l|}{ More than ten times } \\
\hline For any childhood abuse question & & $3.2^{* *}$ & $(1.5,7.0)$ & $4.0^{* *}$ & $(1.7,9.4)$ & $3.7^{* *}$ & $(2.3,6.2)$ & $4.0^{* *}$ & $(2.4,6.8)$ \\
\hline $\begin{array}{l}\text { Slapped on face head or ears, hit or } \\
\text { spanked with something hard }\end{array}$ & & $4.6^{* *}$ & $(1.9,11.0)$ & $5.7^{* *}$ & $(2.0,16.1)$ & $5.1^{* *}$ & $(3.0,8.9)$ & $5.9^{* *}$ & $(3.2,10.8)$ \\
\hline $\begin{array}{l}\text { Pushed, grabbed, shoved, something } \\
\text { thrown at }\end{array}$ & & $4.8^{* *}$ & $(1.7,13.6)$ & $6.0^{* *}$ & $(1.8,20.6)$ & $6.6^{* *}$ & $(3.4,12.9)$ & $6.2^{* *}$ & $(3.2,12.1)$ \\
\hline $\begin{array}{l}\text { Kicked, bit, punched, choked, burned, } \\
\text { attacked }\end{array}$ & & $4.7^{*}$ & $(1.2,18.1)$ & $10.1^{* *}$ & $(1.9,52.8)$ & $5.9^{* *}$ & $(2.4,14.4)$ & $6.1^{* *}$ & $(2.3,16.3)$ \\
\hline $\begin{array}{l}\text { Forced/attempted forced unwanted } \\
\text { sexual activity }\end{array}$ & & 2.0 & $(0.6,7.6)$ & 2.5 & $(0.5,14.1)$ & $3.1^{*}$ & $(1.0,9.5)$ & 2.4 & $(0.7,8.1)$ \\
\hline Unwanted sexual touching & & 2.0 & $(0.7,5.3)$ & 1.8 & $(0.4,7.6)$ & 2.4 & $(0.9,6.2)$ & 1.9 & $(0.7,5.3)$ \\
\hline Exposure to intimate partner violence & & 2.3 & $(0.8,6.4)$ & 3.0 & $(0.9,10.3)$ & $5.0^{* *}$ & $(2.1,12.0)$ & $6.0^{* *}$ & $(2.6,14.1)$ \\
\hline No childhood maltreatment reported & & 0.7 & $(0.3,1.6)$ & 0.9 & $(0.4,2.3)$ & $2.7^{* *}$ & $(1.6,4.4)$ & $3.1^{* *}$ & $(1.8,5.3)$ \\
\hline
\end{tabular}

Source: Statistics Canada, Canadian Community Health Survey -- Mental Health, 2012 (share file)

$\mathrm{Cl}$ Confidence interval

adjusted for sex, income, education, race/ethnicity, and province

bexcluding immigrants to Canada

* Significantly different from reference group $(p<0.05)$

**Significantly different from reference group $(p<0.01)$

observed elsewhere. In Western Australia, reporting of CSA increased almost four-fold following establishment of mandatory reporting requirements [20]. Comparisons among countries with and without mandatory legislation also show higher reporting rates for jurisdictions with mandatory reporting than for those without [21]. The finding that the greatest increase occurred for those reporting the most frequent or serious types of $\mathrm{CM}$ is promising, especially in view of debates regarding over-reporting [22].

The merits of mandatory reporting have been debated [22-26], and some Canadian mental health professionals have called for revocation of such laws [27]. Opponents contend that mandatory reporting increases workload, is intrusive and diverts resources from assisting children and 
families in need [22, 28]. Melton, probably the strongest critic of mandatory reporting, argues that mandatory legislation was created based on a misunderstanding of the nature and scope of CM [22]. Other critics posit that child protection provides only an individual response to what is a broader, societal problem [29]. Advocates of mandatory reporting contend that reporting of $\mathrm{CM}$ to $\mathrm{CPO}$ increase opportunities for beneficial intervention. Clients are generally satisfied with the interaction with a CPO [23], and those who report $\mathrm{CM}$ appreciate the laws related to privacy and confidentiality [30]. Furthermore, increased reporting to CPOs reflects government commitment and brings attention to the problem of CM [24].

The findings of this paper should be interpreted in light of its strengths and limitations. Strengths of this paper include the comprehensive doctrinal legal review that was employed. The statistical analysis used data from a large representative sample of Canadian adults. However, insufficient sample precluded more detailed analysis by specific types of maltreatment and province. Other limitations include the unknown validity of the $\mathrm{CPO}$ measure. It is possible that some respondents who reported $\mathrm{CM}$ were unaware that $\mathrm{CPO}$ involvement occurred or they did not recall the involvement. However, the finding that reported $\mathrm{CPO}$ involvement was rare among those who reported no $\mathrm{CM}$ provides some evidence of the validity of the $\mathrm{CPO}$ measure. The small proportion of respondents who reported CPO involvement but no $\mathrm{CM}$ may have experienced other types of $\mathrm{CM}$ not included in the CCHS MH such as neglect or emotional abuse. As well, reporting of CM may be subject to recall bias. However, evidence of the validity of retrospectively collected CM data is increasing [31-34]. Another limitation was the assumption that the respondent lived in the same province before age 16 as when the CCHS questionnaire was completed. Data from the 2011 National Household Survey indicate that $85 \%$ of the Canadian-born population resides in their province of birth [35]. As well, the study is limited to the household population in Canada's 10 provinces and excludes the territories. Some groups who were not part of the CCHS target population (the homeless, residents of institutions, Indigenous peoples living on reserves, full-time military personnel and the northern territories) have in some studies been found to have elevated levels of CM [36-41]. How this might influence associations between CM and CPO involvement is unknown. Finally, it is possible that secular changes in social values, openness to acknowledge that CM has occurred, family characteristics or other factors may have increased reporting of $\mathrm{CM}$ to $\mathrm{CPOs}$ over time, independent of mandatory reporting laws.

Although it is undisputable that $\mathrm{CM}$ can have devastating immediate and long-term negative consequences, the effects of reporting to $\mathrm{CPO}$ are not well studied. Assuming that $\mathrm{CPO}$ reporting is related to less maltreatment and better outcomes for children, it is encouraging to see that increasing percentages of children who have experienced $\mathrm{CM}$ are being reported to $\mathrm{CPO}$ and that mandatory reporting has assisted in identification of children in need of protection. Unfortunately, this analysis does not inform our understanding about the effectiveness of CPO interventions themselves, such as the provision of services to parents and protective orders for children an important area for future research [25]. Does contact with $\mathrm{CPO}$ and the measures taken by $\mathrm{CPO}$ reduce re-victimisation of children and prevent maltreatment of others? Do children get needed help to treat negative outcomes associated with their exposure to CM?

\section{Conclusions}

This study compiled the history of mandatory reporting to CPO for CSA, CPA and CEIPV in Canadian provinces. The timing of these legislative changes was examined in relation to contacts with $\mathrm{CPO}$ as reported by survey respondents. Evidence from the analysis suggests that the legislation is effective in increasing $\mathrm{CPO}$ involvement. Further study should address if reporting to $\mathrm{CPO}$ is successful in preventing the recurrence of $\mathrm{CM}$ and providing effective assistance to victims and their families since its effectiveness as a public health strategy is unknown. The collection and analysis of longitudinal $\mathrm{CPO}$ data would significantly contribute to such efforts.

\section{Endnotes}

${ }^{1}$ This occurred where the term "sexual abuse" was sometimes not expressly included in the legal provision, but the term "ill-treatment or need for protection" was used, which would embrace sexual ill-treatment or the need for protection because of sexual abuse (and the perception in practice of this by the reporter). Verdun-Jones et al. [14] confirm that sexual abuse was often not expressly included in the initial versions of legislation, but may have been considered in practice as a species of physical ill-treatment, at least in cases of sexual abuse by parents or caregivers; and that subsequently the duty was expressly extended to sexual abuse. An example is Alberta, where the initial enactment of 1966 expressly applied to physical ill-treatment or need for protection, and the subsequent amendment in 1984 expressly included sexual abuse as a category of a child being in need of protection. Similarly, Quebec's initial enactment applying expressly to physical abuse on 28 December 1974 ("physical ill-treatment as the result of abuse or neglect") was enlarged by express inclusion of sexual abuse on 3 April 1984.

\section{Abbreviations}

CCHS-MH: Canadian Community Health Survey-Mental Health;

CEIPV: Childhood exposure to intimate partner violence; CEVQ: Childhood 
exposure to violence questionnaire; Cl: Confidence interval; CM: Childhood maltreatment; CPA: Childhood physical abuse; CPO: Child protection organization; CSA: Childhood sexual abuse; LICO: Low income cutoffs

\section{Acknowledgements}

We thank the participants in the survey for their contribution and CCHS-MH staff. The authors gratefully acknowledge assistance with the preparation of this manuscript from Kathryn Wilkins.

\section{Funding}

Preparation of this article was supported by a Canadian Institutes of Health Research (ClHR) New Investigator Award (Afifi) and a CIHR Foundation Scheme Award (Afifi). No additional funding was received by other authors. $\mathrm{ClHR}$ had no role in the design of the study, nor in the collection, analysis, interpretation of data, nor in writing the manuscript.

\section{Availability of data and materials}

The data are available for analysis from Statistics Canada.

\section{Authors' contributions}

LT wrote the manuscript. BM conducted the doctrinal review and wrote the manuscript. MS conducted the statistical analysis and wrote the manuscript. $L T, B M, M S, W H$ and TA were involved in planning the study, interpreting the data, and providing critical input to the manuscript. All authors have read and approved the final version of the manuscript.

\section{Authors' information}

Lil Tonmyr, Margot E. Shields, Wendy E. Hovdestad are affiliated with the Public Health Agency of Canada. Ben Mathews is affiliated with the Australian Centre for Health Law Research, School of Law, Faculty of Law, Queensland University of Technology, Australia. Tracie O. Afifi is affiliated with the Department of Community Health Sciences, and the Department of Psychiatry, both at the University of Manitoba, Canada.

\section{Ethics approval and consent to participate}

Data for the CCHS - MH were collected on a voluntary basis by Statistics Canada under the provisions of the Statistics Act. CCHS - MH respondents consented to respond to the survey and were asked for permission to share the information they provided with Statistic Canada's partners, which included the Public Health Agency of Canada. This article is based on data from the existing share file and thus the project did not undergo ethics review.

\section{Consent for publication}

Not applicable.

\section{Competing interests}

The authors declare that they have no competing interests. Wendy Hovdestad is an Associate Editor for BMC Public Health.

\section{Publisher's Note}

Springer Nature remains neutral with regard to jurisdictional claims in published maps and institutional affiliations.

\section{Author details}

${ }^{1}$ Public Health Agency of Canada, 785 Carling Ave, AL 6807B, Ottawa, ON K1A 0K9, Canada. ${ }^{2}$ Australian Centre for Health Law Research, School of Law, Faculty of Law, Queensland University of Technology, 2 George St, Brisbane, QLD 4000, Australia. ${ }^{3}$ Department of Community Health Sciences, Department of Psychiatry, University of Manitoba, Winnipeg, MB R3T 2N2, Canada.

Received: 12 March 2018 Accepted: 19 July 2018

Published online: 16 August 2018

\section{References}

1. Gillbert R, Widom CS, Browne K, Fergusson D, Webb E, Janson S. Burden and consequences of child maltreatment in high-income countries. Lancet. 2009;373(9657):68-81.
2. Hovdestad W, Tonmyr L, Wekerle C, Thornton T. Why is childhood maltreatment associated with adolescent substance abuse? A critical review of explanatory models Int J Ment Health Addict. 2011;9:525-42.

3. Tonmyr L, Thornton T, Draca J, Wekerle C. The childhood maltreatment and adolescent substance use relationship: a critical review. Curr Psychiatr Rev. 2010;6(3):223-34.

4. Tonmyr L, Shields M. Child sexual abuse and substance abuse: a gender paradox. Child Abuse Negl. 2017;63:284-94.

5. Afifi TO, MacMillan HL, Boyle M, Taillieau T, Cheung K, Sareen J. Child abuse and mental disorders in Canada. CMAJ. 2014;186(9):E324-32.

6. Poirier D. Social worker enforcement of child welfare legislation: an increasing potential for abuse of power. Can J Fam L. 1986;5:215-35.

7. Dickens B. Legal responses to child abuse in Canada. Can J Fam L. 1978;1: 87-125.

8. Moulton AD, Mercer SL, Popovic T, Briss PA, Goodman RA, Thombley ML, et al. The scientific basis for law as a public health tool. Am J Public Health. 2009:99(1):17-24.

9. MacMillan HL, Jamieson E, Walsh CA. Reported contact with child protection services among those reporting child physical and sexual abuse: results from a community survey. Child Abuse Negl. 2003;27(12): 1397-408.

10. Afifi TO, MacMillan HL, Taillieu T, Cheung K, Turner S, Tonmyr L, Hovdestad W. Relationship between child abuse exposure and reported contact with child protection organizations: Results from the Canadian Community Health Survey. Child Abuse Negl. 2015;46:198-206.

11. Hutchinson T, Duncan N. Defining and describing what we do: doctrinal legal research. Deakin Law Rev. 2012;17(1):83-119.

12. Bessner R. The duty to report child abuse. Can Fam LQ. 1999;17:277-326.

13. Mian M, Bala N, MacMillan H. Child abuse and neglect in Canada. In: Schwartz-Kenney BM, McCauley M, Epstein MA, editors. Child abuse: a global view. Westport: Greenwood Publishing Group; 2001. p. 17-33.

14. Verdun-Jones SN, McLean C, Gregory VH. A survey of policies and practices of government agencies involved in the administration of youth justice and custodial care with respect to complaints of child sexual abuse and complaints by adults of historical child sexual abuse who were provided with government services, whether by employees of the government or by volunteers. Report prepared for the Ministry of Justice of Ontario 2008.

15. Statistics Canada. Canadian community health survey (CCHS)-mental health user guide. Statistics Canada: Ottawa; 2013.

16. Statistics Canada. Canadian community health survey (CCHS)- mental health questionnaire. Statistics Canada: Ottawa; 2011.

17. Walsh CA, MacMillan HL, Trocme N, Jamieson E, Boyle MH. Measurement of victimization in adolescence: development and validation of the childhood experiences of violence questionnaire. Child Abuse Negl. 2008;32(11):1037-57.

18. Brennan S, Taylor-Butts A. Sexual assault in Canada 2004 and 2007. Canadian Centre for Justice Statistics Profile Series. [statistics Canada, catalogue number 85F0033M]. Statistics Canada:: Ottawa; 2008.

19. Statistics Canada. Population by year, by province and territory (CANSIM, table 051-0001). 2015. http://www.statcan.gc.ca/tables-tableaux/sum-som/ 101/cst01/demo02a-eng.htm.

20. Mathews B, Le XJ, Norman RE. Impact of a new mandatory reporting law on identification of child sexual abuse: a seven year time trend analysis. Child Abuse Negl. 2016:56:62-79.

21. Mathews B, Bross DC. Mandated reporting is still a policy with reason: empirical evidence and philosophical grounds. Child Abuse Negl. 2008:32:511-6.

22. Melton GB. Mandated reporting: a policy without reason. Child Abuse Negl. 2005;29:9-18.

23. Drake $B$, Jonson-Reid M. A response to Melton based on best available data. Child Abuse Negl. 2007:31:343-60.

24. Gilbert R, Kemp A, Thoburn J, Sidebotham P, Radford L, Glaser D, MacMillan $\mathrm{HL}$, et al. Recognising and responding to child maltreatment. Lancet. 2009; 373:167-80

25. Gilbert R, Thoburn J, Sidebotham P, Glaser D, HL MM, Kemp A, et al. Authors' reply. Lancet. 2009;373:1251.

26. Mathews B, Payne H. Responding to child maltreatment. Lancet. 2009;373:1250-1.

27. Thompson-Cooper I, Fugere R, Cormier BM. The child abuse reporting laws: an ethical dilemma for professionals. Can J Psychiatr. 1993;38(8):557-62.

28. Ainsworth F. Mandatory reporting of child abuse and neglect: does it really make a difference? Child Fam Soc Work. 2002;7:57-63.

29. Humphreys C. Problems in the system of mandatory repoting of children living with domestic violence. J Fam Stud. 2008;14:228-39. 
30. Serge R, Flaherty E. Forty years later - inconsitencies in reporting of child abuse. Arch Dis Child. 2008;93:822-4.

31. Mills R, Kisley S, Alati R, Stathearn L, Najman J. Self-reported ad agency notified child sexual abuse in a population-based birth cohort. J Psyciatr Res. 2016;74:87-93.

32. Patten SB, Wilkes TC, Williams JV, Lavorato DH, El-Guebaly N, Schopflocher $D$, et al. Retrospective and prospectively assessed childhood adversity in association with major depression, alcohol consumption and painful conditions. Epidemiol Psychiatr Sci. 2015;24:158-65.

33. Reuben A, Moffitt TE, Caspi A, Belsky DW, Harrington H, Shroeder F, et al. Lest we forget: comparing retrospective and prospective assessments of adverse childhood experiences in the prediction of adult health. J Child Psychol Psychiatry. 2016;57(10):1103-12.

34. Scott KM, McLaughlin KA, Smith DAR, Ellis PM. Childhood maltreatment and DSM-IV adult mental disorders: comparison of prospective and retrospective findings. BJP. 2012;200:469-75.

35. Statistics Canada. From east to west: 140 years of interprovincial migration 2017. [cited 2018 June 12] Available from: http://www.statcan.gc.ca/tablestableaux/sum-som/101/cst01/demo02a-eng.htm.

36. Kufeldt K, Nimmo M. Youth on the street: abuse and neglect in the eighties Child Abuse Negl. 1987;11:531-43.

37. Windle M, Windle RC, Scheidt DM, Miller GB. Physical and sexual abuse and associated mental disorders among alcoholic inpatients. Am J Psychiatry. 1995;152:1322-8.

38. Brownridge DA, Taillieu T, Afifi T, Chan KL, Emery C, Lavoie L, Elgar FJ. Child maltreatment and intimate partner violence among indigenous and nonindigenous Canadians. J Fam Violence. 2017;32(1):607-19.

39. Roos LE, Afifi TO, Martin CG, Pietrzak RH, Tsai J, Sareen J. Linking typologies of childhood adversity to adult incarceration: findings from a nationally representative sample. Am J Orthopsychiatry. 2016;86(5):584-93.

40. Afifi TO, Taillieu T, Zamorski MA, Turner S, Cheung K, Sareen J. Association of child abuse exposure with suicidal ideation, suicide plans, and suicide attempts in military personnel and the general population in Canada. JAMA Psychiatrics. 2016;73(3):229-38.

41. Boyce J. Victimization of aboriginal people in Canada, 2014. Canadian Centre for Justice Statistics Profile Series. Statistics Canada: Ottawa (ON); 2016. statistics Canada, catalogue no: $85-002-X$

42. Weithorn L. Protecting children from exposure to domestic violence: the use and abuse of child maltreatment statutes. Hastings Law J. 2001;53:1-156.

Ready to submit your research? Choose BMC and benefit from:

- fast, convenient online submission

- thorough peer review by experienced researchers in your field

- rapid publication on acceptance

- support for research data, including large and complex data types

- gold Open Access which fosters wider collaboration and increased citations

- maximum visibility for your research: over $100 \mathrm{M}$ website views per year

At $\mathrm{BMC}$, research is always in progress.

Learn more biomedcentral.com/submissions 